\title{
Posicionamento Político, Conhecimento Histórico E Pensamento Utópico: Uma Análise Com Dados Quantitativos De Jovens Dos Campos Gerais/Pr - 2017
}

\section{Political Position, Historical Knowledge and Utopian Thinking : A Analysis with Quantatitative Data of People Young of Campos Gerais/ PR -2017}

\author{
Matheus Mendanha Cruz ${ }^{1}$ \\ Universidade Estadual de Ponta Grossa (Brasil)
}

Recibido: 30-01-18

Aprobado: 08-03-18

\section{Resumo}

O texto a seguir tem como base teórica a tendência alemã da Didática da História, principalmente as propostas de Rüsen. O esforço feito foi para relacionar conceitos desse campo de estudo com dados levantados de forma empírica através de questionários respondido por jovens de Ensino Médio da região dos Campos Gerais/PR. As reflexões feitas se debruçaram sobre o conhecimento histórico apresentado pelos estudantes frente as questões sobre o período em que os militares estiveram a frente do governo no Brasil (1964-1985). Os conceitos utilizados para pensar essas respostas foram, de forma mais central, Aprendizado e Formação histórica, além de Pensamento Utópico, e de forma mais ampla Cultura Histórica. Em linhas gerais é possível apontar que os sujeitos que optam por saídas autoritárias sãos os mesmos que demonstraram menor conhecimento sobre o regime que professam como modelo para solucionar os problemas do Brasil.

\footnotetext{
${ }^{1}$ (matheusmcruz@live.com) Bolsista Capes; Mestrando em História pela Universidade Estadual de Ponta Grossa - UEPG; Licenciado em História pela UEPG; integra o Grupo de Estudo em Didática da História - GEDHI; atua na escola pública do estado de Santa Catarina; é autor do livro Descobrimento do Brasil: da Historiografia para os Manuais Didáticos publicado pela Chiado Editora em 2016; também autor, dentre outros trabalhos, do artigo "Posicionamiento político de los jóvenes y conocimiento histórico: un estudio empírico en los Campos Gerais, Paraná, Brasil” publicado pela revista Clio \& Asociados. La Historia enseñada, 2017 (25).
} 
Palavras-chave: Aprendizado Histórico. Formação Histórica. Cultura Histórica. Pensamento Utópico. Ditadura Civil-Militar Brasileira.

\begin{abstract}
The text hereinafter have with theoretical basis the german tendency of Historical of Didatic, primarily the proposals of Rüsen. The effort made was to relate concepts that field os study with data collected of empirically through of questionnaires answered by youngs of the High School of region of Campos Gerais / PR. The reflections made supported about the period where the military were in front of government in Brasil (1964-1985). The concepts used to thinking that answers were, in order to central, Learning and Historical Education, beyond of utopian thinking, and of form more wide Historical Culture. In general lines it is possible point what the persons what opted for authoritarian exits were the same what demonstrated smaller knowledge about the regime what profess as model for solve the problems of the Brasil.
\end{abstract}

Key-words: Historical Learning. Historical Education. Historical Culture. Utopian Thinking. Civil Military Dictatorship.

\title{
Motivações e Metodologia
}

A pesquisa aqui apresentada surgiu da observação de um movimento que ganhou força nos últimos anos a favor dos governos liderados pelos militares no Brasil entre os anos de 1964-1985. O que mais gerou incômodo investigativo foi a presença de jovens que não viveram aquela época e, mesmo assim, defendem a intervenção militar e a volta dos Generais ao poder (Platanow, 2015).

O incômodo de jovens que não viveram o período se colocarem a favor do governo dos militares não é ressaltado somente por nós, o que mostra a pertinência da discussão que propomos aqui. Juliana Balestra destaca que em 2015 houve movimentos de apoio à volta dos militares ao poder e, segundo a autora, (...)

(...) o fato curioso é que elas contaram com a participação de jovens e adultos que não viveram a fase adulta durante o período, o que revela como estão as disputas sobre esse passado no país e dão a exata medida da fragilidade da nossa democracia (Balestra, 2016, p. 250).

Esses movimentos em prol da intervenção dos militares começaram a ganhar força no decorrer de um processo de contraposição à presidente Dilma, que resultou no Impeachment, e ganhou espaço considerável na imprensa. 
Embora não seja a totalidade dos brasileiros que apoiassem a pressão para a queda da presidente eleita, e nem fosse a totalidade de manifestantes que pedissem o retorno dos militares ao poder, é um dado a considerar a presença e a atenção adquirida através da divulgação desta ideia.

Há também movimentos de juventude voltados a uma atuação política mais prática, com ações e discursos, que estão em desacordo com o que defendem os simpatizantes dos governos dos generais. O exemplo disto é que no ano passado, 2016, o Brasil viu várias escolas sendo ocupadas pelos estudantes que protestavam contra as alterações no Ensino Médio (ARede, 2016), inclusive escolas que coletamos dados para a presente pesquisa.

Um dos objetivos almejados na presente discussão é estabelecer um panorama local sobre o posicionamento dos jovens frente ao período dos governos liderados pelos militares, levando em conta essas contradições. Esse objetivo ganha importância quando observamos a ocupação das escolas por parte dos estudantes e o protesto ativo de outra parte que era contra o discurso político e os métodos de ação adotados pelos que ocuparam (Notícias.cidades, 2016).

Buscar compreender o posicionamento político desses jovens e ter uma noção, ainda que geral, dos meios que os mesmos utilizam para embasar suas opiniões ajuda a refletir sobre quais tem sido os caminhos para a formação do pensamento político atual.

E refletindo sobre essa formação do pensamento político que, também, é possível pensar sobre o caminho que o conhecimento histórico tem trilhado. Quando há o esforço de se debruçar sobre temas como o do governo dos Generais e vê-se o crescimento de um posicionamento favorável a tal governo é possível concluir que há, para além da historiografia, meios que estão influenciando fortemente essas tomadas de posição, uma vez que a historiografia, de forma geral, se contrapõe a esse período.

A pesquisa do projeto Jovens e a História ${ }^{2}$, que teve seus dados levantados em 2012 e 2013, ajuda embasar a conclusão, já apontada por Rüsen (2010a, p. 97) de forma teórica, de que o posicionamento é construído com algo que está além das aulas de História, como os círculos familiares, cibercultura e, também, os meios de comunicação tradicionais (Cerri L. F., 2016, p. 97). Essa pesquisa, Jovens e a História, foi realizada por meio de questionários com

\footnotetext{
${ }^{2}$ A pesquisa do projeto Jovens e a História surgiu com base no projeto europeu Youth and History, que acabou por influenciar a reestruturação da Didática da História através de análises quantitativas que visavam discutir o conceito de Consciência Histórica. O projeto Jovens e a História está voltado para discutir a mesma temática, Consciência Histórica, na América Latina, mais especificamente no Mercosul. Para isso elaborou-se questionários que foram aplicados em jovens de 15 anos, e seus respectivos professores, em 4 países (Brasil, Argentina, Uruguai e Chile) com as seguintes características: utilizou-se da escala Likert; foi composto por 43 questões o dos alunos e 21 o dos professores; no total foram aplicados 3913 questionários em alunos e 267 em professores (Barom, 2017, pp. 130-131).
} 
jovens de várias escolas e regiões de Brasil, Argentina, Uruguai e Chile. Os dados coletados possibilitam enxergar tendências políticas e de interpretação histórica dos jovens brasileiros que fornecem base para pensar o posicionamento desses estudantes frente ao governo dos Generais.

Uma das tendências identificadas é que "a posição que predomina entre os jovens brasileiros, no final das contas, oscila entre a indiferença e uma avaliação - tênue - de que a ditadura teve aspectos negativos, mas também positivos" (CERRI \& DUARTE, 2012, p. 249). Esse posicionamento se difere dos jovens uruguaios e argentinos que se colocam mais veementemente contra os regimes militares de seus respectivos países (CERRI \& DUARTE, 2012, p. 249). O panorama que é possível observar no referido texto é que "a avaliação dos jovens sobre o futuro é pessimista, estabelecendo-se então quase uma continuidade direta com as questões problemáticas do passado, projetando sua manutenção ou aprofundamento" (CERRI \& DUARTE, 2012, p. 242). Corroborando esses dados o trabalho de Penna (2015) também aponta para uma desesperança no futuro por parte da juventude.

Em um outro texto Cerri (2016, p. 96) indica, baseado nos dados empíricos levantados pelo projeto Jovens e a História, que o posicionamento dos jovens brasileiros frente ao período em que os militares estiveram à frente do poder ocorre, em grande parte, por falta de conhecimento histórico sobre o período, mais do que por conservadorismo convicto.

Juliana Balestra (2016, p. 270) chega a mesma conclusão sobre esse assunto apontando a falta de conhecimento referente ao assunto como fator principal para tal. A autora, em seu texto, compara a relação de brasileiros e argentinos frente, respectivamente, aos seus últimos regimes ditatoriais utilizando como fonte publicações oficias e ações dos respectivos governos tendo em conta o período tratado. O que ela observa é que os jovens argentinos têm mais contato com as discussões referente ao governo liderado pelos militares no seu país, uma vez que há investimento e esforço do governo para divulgar as atrocidades e discutir valorizando a memória e os lugares de memória. Em contrapartida, no Brasil discute-se pouco sobre os anos em que generais governaram o país, pelo contrário, (...)

(...) a abordagem recorrente no ensino de história persistiu muito tempo com a ideia de que não cabe à História ou ao seu ensino tomar partido nas disputas sobre a construção de memórias e, com isso, se perpetua a estratégia de não estudar a história "mais recente". O principal argumento é que essa história ainda não foi escrita e, portanto, não pode ser ensinada. Além disso, ela poderia gerar certos constrangimentos, porque muitos dos principais protagonistas desse passado ainda estão vivos e ativos na arena político-social (Balestra, 2016, p. 258). 
A presente pesquisa partiu do interesse de compreender se os jovens têm, de forma geral, apoiado, se contraposto ou mantido a indiferença acerca do regime dos generais. Assim bem como buscou-se construir um panorama que permita ter informações sobre o conhecimento desses sujeitos sobre o período tratado, pensando nesse conhecimento sobre o passado, ou a falta dele, como fundamentos de suas opiniões no presente.

Para a coleta de dados visando alcançar os objetivos já descritos acima foi utilizado o método de pesquisa através de questionário quantitativo, ou survey. Günther (2003, p.1) aponta como três os caminhos principais para pesquisas em ciências sociais empíricas: observar o comportamento que ocorre de modo natural; observar o comportamento em situações criadas; e, por fim, perguntar as pessoas o que elas pensam e/ou fazem. É dentro dessa última perspectiva que a presente pesquisa se enquadra, por ela "assegurar melhor representatividade e [permitir] generalização para uma população mais ampla" (GÜNTHER, 2003, p.1).

Os questionários foram aplicados entre os dias vinte e seis de maio (26/05) e vinte e oito de junho (28/06) de 2017no Ensino Médio de cinco escolas da região dos Campos Gerais, sendo elas classificadas como: Pública de Excelência; Pública de Periferia; Pública Central; Privada Confessional; e Privada Laica. O questionário foi impresso em folha A4 e aplicado, durante aulas de História, nos alunos que, de modo voluntário, responderam as questões.

Para a análise foram utilizados os dados computados e o cruzamento entre as respostas de cada escola dentro da técnica da estatística descritiva. $\mathrm{O}$ intuito desse cruzamento não é hierarquizar as instituições, mas compreender os posicionamentos dos alunos tendo por base as ideias de que a escola forma, transforma ou reforça os saberes do senso comum (GRAMSCI, 1991; BOURDIEU, 2013; FREIRE, 1996).

Para a discussão feita no presente trabalho foi utilizada a porcentagem de marcação para cada resposta e nos gráficos constam apenas as respostas válidas, afim de comparar quais as opções que constavam no questionário mais refletem a ideia da juventude entrevistada. A única questão que não foi utilizada a porcentagem e sim a soma total de cada marcação por opção foi a referente aos meios pelos quais os estudantes julgam mais confiáveis obter informações sobre o período em que os militares estiveram à frente do país. O total de questionários foi de 339, sendo 71 da Escola Pública de Excelência; 54 da Escola Privada Confessional; 45 da Escola de Periferia; 94 da Escola Pública Central; e 75 da Escola Privada Laica. A maioria dessas escolas estão localizadas na cidade de Ponta Grossa - PR, entretanto a escola Privada Laica situa-se na cidade de Castro - PR, que pertence a mesma região que Ponta Grossa, Campos Gerais. As escolas em que foi aplicado o questionário abriram as suas portas de forma voluntária e por isso, devido as dificuldades de adentrar as escolas 
para se fazer pesquisa, que apenas uma escola não é da cidade de Ponta Grossa. Sendo importante também destacar que não há pretensão que seja uma amostra estatística, pois a pesquisa foi feita em escolas que, voluntariamente, abriram as portas para que o questionário fosse aplicado.

Quanto aos gráficos que constam no corpo do trabalho foram gerados através dos softwares Word e Excel e o cruzamento de dados foi feito através do SSPS. A intenção nos gráficos foi fazê-lo, na maioria das vezes, com porcentagem para que pudesse ficar mais claro a proporção, para a análise, entre as escolas e/ou grupos.

Para ficar mais claro, segue um panorama em tópicos do que foi o questionário aplicado dividindo-o em grupos de questões:

a) Questões sobre conhecimento escolar e sua relação com o governo dos generais;

b) Questões sobre o conceito que os estudantes têm dos governos dos generais;

c) Questões sobre conhecimentos históricos sobre os governos dos generais;

d) Questões sobre os meios de informação e sua confiabilidade para formação de conhecimento histórico;

e) Questões sobre posicionamento dos jovens frente à política atual;

\section{Didática da História, Consciência Histórica e Cultura Histórica}

O presente texto tem como intuito relacionar o posicionamento político apresentado pelos jovens entrevistados e o conhecimento histórico manifestado. Essa reflexão está baseada, principalmente, na dimensão política da Cultura Histórica exposta por Rüsen (2015, pp. 232-233).

Dedicaremos aqui um espaço para discorrer sobre alguns conceitos utilizados aqui para a reflexão sobre as dimensões da Cultura Histórica. Esses conceitos encontram-se dentro do campo de estudos da Didática da História.

Segundo Rüsen (2015, p. 248), esse campo possui um arcabouço próprio de tarefas, sendo responsável por pesquisar e refletir sobre a aprendizagem histórica. É também necessário apontar que esse campo está dentro da ciência da História e não da Educação, como bem demonstra Oldimar Cardoso (2008) e Rafael Saddi (2010).

Cerri (2010) difere um pouco da posição desses dois autores porque defende que Didática da História é um campo interdisciplinar. Esse posicionamento de Cerri foi explicado por Saddi (2010, p. 65) quando este afirma que (...) 
(...) Cerri percebe que, embora o pensamento alemão apresente a Didática da História como uma disciplina da Ciência Histórica, na prática, não há uma disciplina no Brasil, mas uma área de interesse interdisciplinar conhecida por Ensino de História.

O posicionamento de Cerri traz o benefício ao campo da aproximação da interdisciplinaridade, arejando assim as discussões e possibilitando uma ampliação da discussão se aproximando, por esse caminho mais interdisciplinar, as propostas e reflexões de pesquisa do cotidiano das questões que anseiam por respostas dentro da sociedade. Essa necessidade da aproximação de outras disciplinas para melhor compreensão da vida prática é defendida claramente por Saddi (2010, p. 78).

O que esses autores têm em comum é a concepção de que a Didática da História é o campo responsável por pesquisar e refletir sobre a construção do conhecimento histórico dentro da sociedade e por aproximar a história dos problemas cotidianos da vida prática (SADDI, 2010, p.78; CERRI, 2010, p.267; CARDOSO, 2008, p. 158).

Sendo assim, existem alguns conceitos utilizados dentro desse campo que nos possibilitam compreender melhor os processos de circulação e construção do conhecimento histórico dentro do cotidiano das sociedades. Um deles, e o central dentro da linha a que nos filiamos aqui ${ }^{3}$, é o de Consciência Histórica.

Consciência Histórica refere-se à interpretação do passado visando a orientação no presente, levando em conta a subjetividade e o contexto do sujeito (RÜSEN, 2010a, p. 33-34). Esse papel está voltado à constituição de sentido, ou seja, é a Consciência Histórica responsável por pegar a experiência do passado e organizá-la para que possa orientar o presente e também criar perspectivas de futuro (Rüsen, Teoria da História: Uma teoria da história como ciência, 2015, pp. 41-42). É importante ainda destacar que para Rüsen e Heller, segundo Cerri (2001, p. 99), a consciência histórica é inerente a todas as pessoas.

Outro conceito que é ímpar para a compreensão da atuação da Consciência Histórica é a Cultura Histórica. Para Oldimar Cardoso (2008, p. 159) "Cultura Histórica é a forma de expressão da Consciência Histórica" e essa definição está de acordo com a de Rüsen (2015, p. 217), quando este afirma que "Cultura Histórica é o suprassumo dos sentidos constituídos pela consciência histórica humana. Ela abrange as práticas culturais de orientação do sofrer e do agir humanos no tempo".

Essa Cultura Histórica, segundo Rüsen (2015, p. 229), divide-se em 5 dimensões, sendo essa divisão didática, uma vez que no cotidiano elas são interdependentes (Rüsen, Teoria da História: Uma teoria da história como

${ }^{3}$ Saddi (2014, p. 138) explica que das demais tendências da Didática da História existentes na Alemanha na década de 1970 o grupo que saiu mais fortalecido, sendo este que chegou com mais foça ao Brasil, é o que se organizou em torno justamente do conceito de Consciência Histórica.

Araucaria. Revista Iberoamericana de Filosofia, Politica, Humanidades y Relaciones Internacionales, año $21, \mathrm{n}^{\circ} 41$. Primer semestre de 2019. Pp. 187-208. ISSN 1575-6823 e-ISSN 2340-2199 doi: 10.12795/araucaria.2019.i41.09 
ciência, 2015, p. 235). As dimensões são cognitiva, que refere-se ao sentido de verdade empregado em determinado discurso; estética, que é a responsável por humanizar, de certa forma, o conhecimento, torna ele perceptível ao sujeito; política, refere-se a legitimidade dos argumentos expostos pelo discurso, é a responsável por lidar com o pensamento histórico no que tange as lutas pelo poder; moral, essa dimensão liga a Cultura Histórica aos conceitos de ética e moralidade, colocando os discursos dentro da díade certo-errado; e religiosa, que está ligada a ideia de uma salvação, essa dimensão se encontra muito presente também em organizações teleológica de fatos (Rüsen, Teoria da História: Uma teoria da história como ciência, 2015, pp. 231-234).

É interessante observar que essas dimensões propostas por Rüsen e apresentadas aqui sofreram uma mudança desde a proposta feita pelo autor na primeira metade da década de 1990. Em texto traduzido para o espanhol sob o título ¿Qué es la Cultura Historica?: reflexiones sobre una nueva manera de abordar la historia, originalmente publicado em 1994, o autor propõe apenas 3 dimensões, sendo elas: estética, política e cognitiva.

No texto mais recente Rüsen (2015) defende que para a ciência histórica é essencial as dimensões política, estética e cognitiva, mas que na atuação da Cultura Histórica dentro do cotidiano dos sujeitos não é possível ignorar as dimensões moral e religiosa, por estar ligada intrinsecamente mesmo aos historiadores (Rüsen, Teoria da História: Uma teoria da história como ciência, 2015, p. 230).

\section{Cultura Histórica e Posicionamento Político}

Dentro das dimensões da Cultura Histórica que trabalhamos anteriormente, a dimensão política é a responsável por legitimar um discurso/memória. Aqui reproduziremos uma citação de Rüsen por esta demonstrar a importância da história e do passado para a dinâmica política:

\footnotetext{
Nas relações autoritárias de dominação, os historiadores estão constantemente sob suspeita de contestar a legitimação, pois são capazes de apresentar experiências de desumanidade conectadas com problemas de dominação ou relações de dominação alternativas, mais humanas. Nos sistemas políticos em que o exercício do poder e da dominação dependa da adesão de sujeitos livres (cidadãos e cidadãs), o pensamento histórico assume a função legitimadora de manter viva a liberdade humana (Rüsen, Teoria da História: Uma teoria da história como ciência, 2015, p. 233).
}

Prova desta dimensão política da Cultura Histórica é o livro de Marc Ferro (1989), A História Vigiada, em que o autor se debruça sobre os usos e tensões 
dentro da sociedade referentes aos discursos históricos e o passado. Ainda outro trabalho que versa um pouco sobre as tensões em torno da história pela sua dimensão política é o de Laville (1999), uma vez que demonstra as lutas e desdobramentos em torno do ensino de história nas escolas e seu papel social.

Dentro da escola ainda temos trabalhos como o de Joana Neves (2000/2001) que demonstram as tensões acerca da história a ser ensinada, no caso específico, como a memória, ou história produzida por outros que não historiadores, tem se colocado contra a historiografia na hora de ser ensinada em sala de aula.

Koselleck também demonstra essa dimensão política que a Cultura Histórica exerce quando cita um relato de Friedrich Von Raumer, um historiógrafo do século XIX:

\begin{abstract}
Durante uma reunião, Oelsen, chefe de departamento no Ministério das Finanças, defendia vivamente a impressão de grande papel-moeda para pagar dívidas. Uma vez esgotados os argumentos contrários, eu (conhecendo meu homem) disse com demasiada ousadia. "Mas senhor Conselheiro Privado, o senhor certamente se lembra que já Tucídides falava do mal que sucedeu quando, em Atenas, decidiu-se imprimir papel-moeda em grande quantidade". "Essa é uma experiência de grande importância", ele retrucou em tom conciliador, deixando-se assim convencer, para manter a aparência de erudição (Koselleck, 2006a, p. 41).
\end{abstract}

Após citar esse evento Koselleck (2006a, p. 41) explica que "o conselheiro se apega a fórmula, e não a um argumento em objetivo". Com essa afirmação o autor lança luz ao debate, bastante atual, sobre a dimensão política, mas também estética da Cultura Histórica. Isso perpassando pelas lutas presentes sobre o domínio das narrativas e o surgimento e fortalecimento de materiais como Brasil Paralelo $^{4}$, que, embora não seja feito por historiadores, declara como objetivo contar a história, com uma pretensão salvífica, típica da dimensão religiosa, que foi escondida até então e tem uma estética bastante convincente.

Os dados que discutiremos a seguir referem-se ao conhecimento histórico e ao posicionamento político, pensando se há embasamento sobre o período do governo dos generais para os posicionamentos que os jovens entrevistados manifestam.

\footnotetext{
${ }^{4}$ Sobre o material do Brasil Paralelo o professor Luis Fernando Cerri em seu canal do YouTube História Recente traça alguns comentários esclarecedores acerca do estilo de história adotado pelos idealizadores dos documentários. Melhor Série: Brasil Paralelo ou Lost?. Disponível em: https:// www.youtube.com/watch?v=17rvmtivHJw\&feature=youtu.be. Acessado em: 17/12/2017.
} 


\section{Aprendizado Histórico}

O conhecimento histórico é fator importante na discussão acerca de posicionamento político porque é a gama de conhecimentos sobre o passado que permite a tomada de atitude e a orientação dos sujeitos no presente e também suas perspectivas de futuro. Rüsen (2001, p. 10) denomina esse processo de geração de sentido. Sendo assim, perceber aquilo que os jovens têm de conhecimento quanto algum assunto possibilita compreender como estão sendo gerado suas opiniões políticas.

Essa reflexão é importante, uma vez que "antes mesmo que o passado seja abordado no modo típico de uma disciplina especializada, elaborado pela pesquisa e tornado presente pela historiografia, ele sempre atua nos contextos da vida prática atual" (Rüsen, Teoria da História: Uma teoria da história como ciência, 2015, p. 37). Ou seja, o passado se faz presente no cotidiano, mediante as memórias e saberes transmitidos por instituições, grupos sociais e meios de comunicação, mas compreender o papel que a História como ciência tem, uma vez que o passado interfere na legitimidade de discursos, é fundamental para entender a dinâmica dos posicionamentos políticos.

Para compreender o processo de formação do conhecimento histórico e sua pertinência para a discussão sobre posicionamento político utilizaremos os conceitos de Formação e Aprendizado Histórico propostos por Rüsen. O primeiro refere-se ao (...)

[...] modo de recepcionar esse saber (histórico) e lidar com ele, de tomar posição quanto a ele, de utilizá-lo (...) ela [formação] é característica de todos os que desejam ou precisam efetivar sua compreensão do mundo e de si, na orientação da vida prática, em um determinado nível cognitivo (RÜSEN, 2010a, p. 101).

Já Aprendizado Histórico, para Rüsen (2010b, p. 43), só ocorre quando se parte de problemas verdadeiros do presente do sujeito e o próprio sujeito afere sentido aquilo que está aprendendo, do contrário não há Aprendizado Histórico. Ou seja, "o Aprendizado Histórico pode, portanto, ser compreendido como um processo mental de construção de sentido sobre a experiência do tempo através da narrativa histórica" (Rüsen, Aprendizado Histórico, 2010b, p. 43).

Sendo assim, "Formação baseia-se no Aprendizado e é, simultaneamente, um modo próprio de Aprendizado" (RÜSEN, 2010a, p. 104). Faz parte, por exemplo, da Formação aprender a ter leitura de mundo, como nos ensina Freire (1989). Pois, o sujeito que possui esse tipo de leitura, recebe as informações que lhes são postas à frente, ou conquistadas, de forma diferenciada.

Com tudo isso é possível perceber que Rüsen (2015, p. 252) destaca que o Aprendizado Histórico ocorre mediante a aquisição de competências, no caso, destacamos aqui, a competência de pensar historicamente. Para o autor, essa 
competência refere-se a pessoa estar "apta a narrar históricas de que tem necessidade para dar conta da dimensão temporal de sua própria vida prática" (Rüsen, Teoria da História: Uma teoria da história como ciência, 2015, p. 252).

Se a competência de pensar historicamente é o que é colocado em foco por Rüsen e ela ocorre através do Aprendizado Histórico ${ }^{5}$, ela só pode ocorrer se houver conteúdo para haver a interpretação e a reflexão. Por esse fator, também, que as questões apresentadas por nós através do questionário não se referem a interpretações, mas sim a fatos.

Por fim, é importante destacar a afirmação de Rüsen (2015, p. 260): “a formação da identidade é, pois, uma das funções mais importantes, se não a mais importante, do pensamento histórico na vida prática de cada época". Com essa competência de organizar as histórias do passado para lhe permitir uma identidade no presente é que os dados que apresentaremos a seguir visam discutir. Objetivamos traçar comparações entre o que os posicionamentos políticos frente aos problemas atuais do Brasil refletem sobre o conhecimento do passado.

\section{Conhecimento Histórico E Posicionamento Político}

Os gráficos a seguir referem-se as questões que perguntavam quem foi o presidente deposto pelos militares e quem foram os presidentes generais no período em que os militares estiveram à frente do país. A intenção é perguntar sobre o conhecimento apresentado pelos jovens respondentes sobre o período em que os militares governaram o Brasil ${ }^{6}$.

\section{Qual presidente foi deposto quando os militares chegaram ao poder em 1964?}

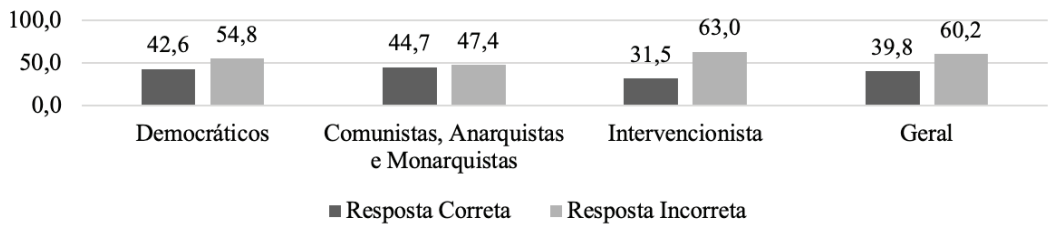

Gráfico 1 - Qual presidente foi deposto em 1964: Categórico7

Fonte: $\mathrm{O}$ autor

5 "O aprendizado histórico resulta em aumento de competência interpretativa" (RÜSEN, 2010a, p. 114).

${ }^{6}$ As categorias apresentadas nos gráficos no decorrer do texto baseiam-se nas respostas da pergunta Qual seria a solução para o Brasil?, contida no instrumento de pesquisa. Sendo assim, Democráticos, que são os que escolheram as opções de Eleições Gerais Já ou permanência do atual governo até 2018; Intervencionistas, que são os que optaram pelas opções de Implantar uma Ditadura, uma Intervenção Militar e Fechamento da Câmara dos Deputados e Senado; por fim, os que escolheram as opções de Revolução Comunista, Revolução Anarquista ou Entregar o Governo para os herdeiros de D. Pedro II.

7 As opções de respostas eram Jânio Quadros; Getúlio Vargas; Juscelino Kubitschek; e João Goulart. 


\section{Quais os presidentes-generais dos governos militares (1964-} 1985)?

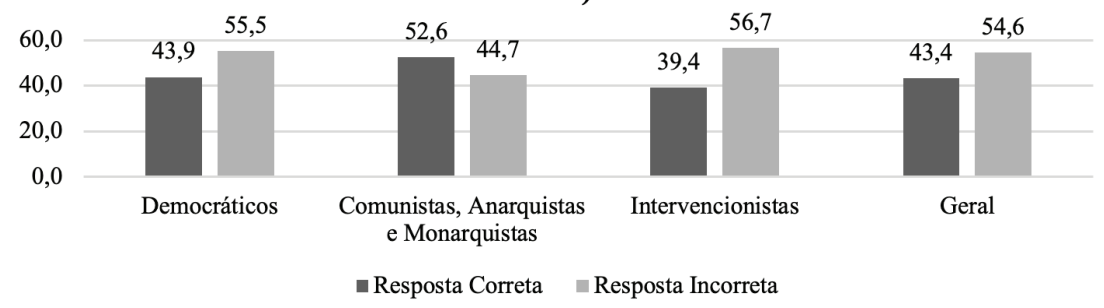

Gráfico 2 - Quais os Presidentes-Generais: Categórico ${ }^{8}$

Fonte: $\mathrm{O}$ autor

No Gráfico 1 é possível perceber que, no geral, os estudantes entrevistados erram quem foi o presidente deposto pelos militares. Entretanto, dividindo em categorias os estudantes, os que mais erram a questão são os intervencionistas, seguidos pelos democráticos e os comunistas, anarquistas e monarquistas, praticamente divididos meio a meio.

No Gráfico 2 a maioria dos estudantes, mais uma vez, erra a resposta. Novamente os intervencionistas são os que mais erram, seguidos de perto pelos democráticos. A exceção são os comunistas, anarquistas e monarquistas que, dentro dessa categoria, a maioria dos estudantes entrevistados acerta quem foram os presidentes-generais no período em que o Brasil foi governado pelos militares.

É interessante observar esses dados e perceber que os que menos apresentam conhecimento sobre o período em que os militares estiveram à frente do poder são justamente os que pedem pela volta deles ao governo do Brasil.

O gráfico a seguir apresenta os dados, divididos nas mesmas categorias, referentes às respostas sobre qual foi o destino dos torturadores do regime. A intenção do gráfico a seguir é mapear a manifestação do conhecimento dos respondentes quanto o final do regime.

\footnotetext{
${ }^{8}$ As opções de respostas eram: Juscelino Kubitschek, João Goulart, Jânio Quadros, Eurico Gaspar Dutra; Castelo Branco, Costa e Silva, Garrastazu Médici, Ernesto Geisel, João Baptista Figueiredo; Costa e Silva, Garrastazu Médici, José Sarney, Itamar Franco; Castelo Branco, Ernesto Geisel, Fernando Henrique Cardoso, Pedro Aleixo, João Goulart.
} 


\section{O que aconteceu com os torturadores dos governos militares com o processo de redemocratização?}

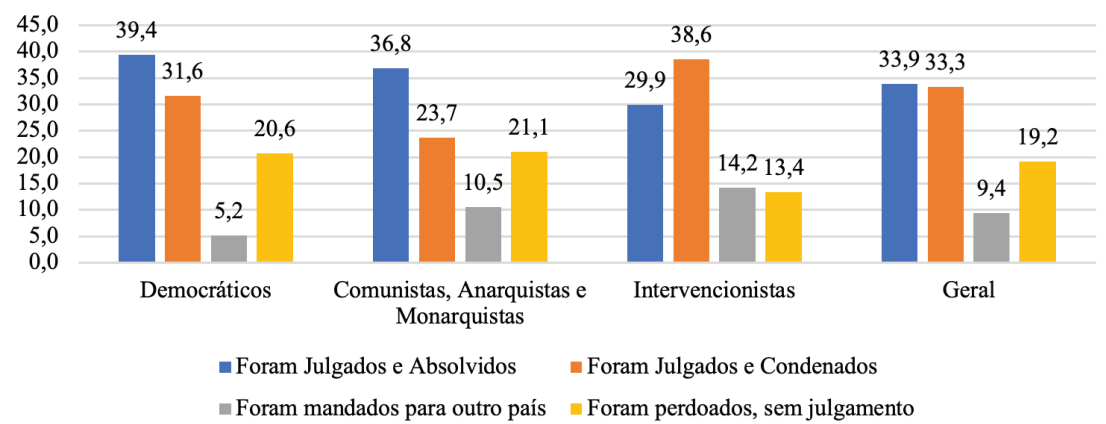

Gráfico 3 - O que aconteceu com os torturadores dos governos militares: Categórico e Geral Fonte: $\mathrm{O}$ autor

O que é possível perceber é que todos os grupos afirmam que houve julgamento para os torturadores do período em que os militares estiveram à frente do governo. Entretanto, o grupo que teve maior porcentagem de acertos foi, novamente, os comunistas, anarquistas e monarquistas, seguidos de muito perto pelos democráticos.

O que vale a pena ressaltar aqui é que os intervencionistas tornam a ser o grupo em que há menos acerto da questão. Mas, frente as respostas, talvez o mais interessante a ser destacado é que é o grupo em que a opção mais marcada foi que os torturadores foram julgados e condenados, enquanto que nas outras categorias a opção mais marcada foi que foram julgados e absolvidos.

Dentre as opções apresentadas, se podemos assim estabelecer, a mais errada dentre as quatro é, justamente, a que afirma que os militares foram julgados e condenados. Isso porque, além de não haver julgamento, passou longe de haver condenação. Ou seja, enquanto todas as opções apontavam para a absolvição a única que apontava para um sentido contrário seria essa que foi a mais marcada pelos intervencionistas.

O próximo gráfico apresenta uma questão em que o pensamento histórico precisa atuar, uma vez que requer interpretação e conceituação. A questão que permitiu gerar os dados perguntava sobre qual o modo que os militares chegaram ao poder em 1964. 


\section{Como os generais do regime de 1964 chegaram ao poder?}

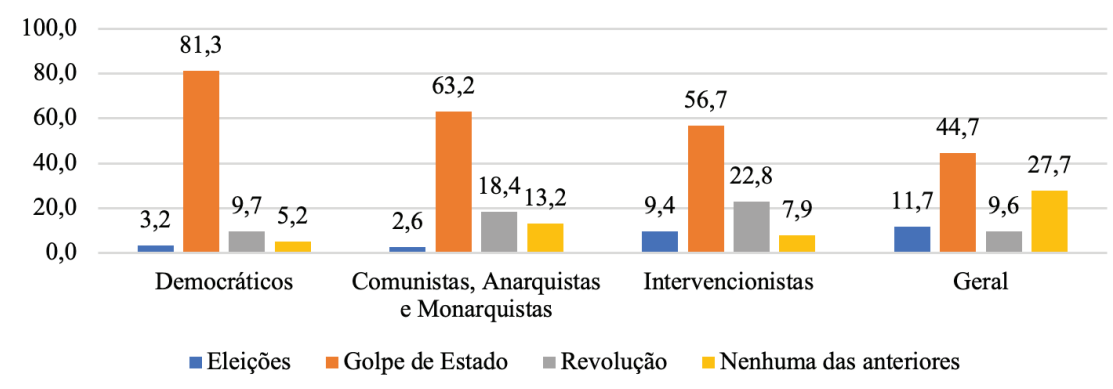

Gráfico 4 - Como os militares chegaram ao poder: Categórico e Geral

Fonte: $\mathrm{O}$ autor

É interessante observar nesses dados que os democráticos são os que mais defendem a ideia de que a chegada ao poder dos militares se deu através de um Golpe de Estado. Depois dos democráticos vem os posicionamentos mais extremos (comunistas, anarquistas e monarquistas) esses consideram significativamente 1964 como Golpe de estado, mas dobra a porcentagem daqueles que julgam como revolução. Já os intervencionistas, sua maioria, admite o movimento de 1964 como Golpe de Estado, entretanto uma maioria menor, se comparado aos outros grupos apresentados. E são os intervencionistas o grupo que mais marca a chegada ao poder dos militares por vias eleitorais, o que factualmente não ocorreu, e também uma chegada através de uma Revolução, que foi o discurso da época e que tem ressurgido ultimamente ${ }^{9}$. No geral, os jovens admitem 1964 como Golpe de Estado, mas uma porcentagem significativa não aponta nenhuma das opções como suficientes para definir o movimento que originou o regime liderado pelos militares.

\section{História E Posicionamento Político}

Através dos dados apresentados é possível perceber, dentre as categorias que utilizamos para a análise, que os intervencionistas são os que mais erraram as questões referentes a conhecimento histórico sobre o período dos militares.

\footnotetext{
9 As matérias a seguir são, respectivamente, dos anos de 2014 e 2013. Professor de Direito da USP trata golpe de 64 como revolução. Disponível em: http://www1.folha.uol.com.br/ poder/2014/04/1435203-professor-de-direito-da-usp-trata-golpe-de-64-como-revolucao-leiaintegra.shtml. Acessado em: 04/11/2017. Ao citar ditadura em discurso, Aécio fala em 'revolução de 64'. Disponível em: http://www1.folha.uol.com.br/poder/2013/04/1257153-ao-citar-ditadura-emdiscurso-aecio-fala-em-revolucao-de-64.shtml. Acessado em: 04/11/2017.
} 
Utilizando a discussão sobre Aprendizado Histórico e Formação, é possível apontar que os intervencionistas são os que menos apresentam possibilidades de desenvolver a competência narrativa, uma vez que para isso precisam organizar os fatos e não apresentaram, em sua maioria, conhecimento sobre eles.

Bodo Von Borries ${ }^{10}$ (2016), sobre a relação entre conhecimento acontecimental $^{11}$ sobre o passado e a dinâmica da competência narrativa, destaca que "as pessoas podem saber um conjunto de datas (reinos, batalhas, tratados, invenções, etc.), sem serem aptas para narrar a história de alguma forma" (Borries, 2016, p. 177).

Para esse autor "a qualificação do pensamento, trabalho, argumentação e julgamento de uma maneira histórica podem ser os objetivos da aprendizagem histórica (...) isto nunca pode ser aprendido com um 'conteúdo"' (Borries, 2016, p. 178). As ideias que o autor apresenta parecem um pouco controversas porque, apesar de ele afirmar que as competências nunca podem ser aprendidas com conteúdo e que saber o conteúdo não é garantia de aquisição das competências, o que concordamos, ele afirma mais a frente em seu texto que (...)

(...) história são dois mundos, um de conteúdo, temas e tópicos; o outro de ferramentas, habilidades, métodos, teorias. Ambos não são completamente independentes: há uma ligação entre eles no mundo das noções, conceitos, estruturas e categorias (Borries, 2016, p. 179).

Para o nosso presente texto gostaríamos de defender que habilidades e conteúdos são, de certa forma, esferas dependentes da História e que sem o conteúdo não é possível elaborar as narrativas e sem a competência de pensar historicamente os fatos, por si só, não são capazes de gerar sentido.

A falta do desenvolvimento dessa competência prejudica a orientação nas ações e posicionamentos do presente, uma vez que "o Aprendizado Histórico acarreta aumento da competência de orientação" (RÜSEN, 2010a, p. 116). O aumento da competência narrativa gera autonomia nas convicções, no caso políticas, uma vez que o Aprendizado Histórico permite o desenvolvimento da habilidade de interpretar e compreender o mundo a volta mobilizando informações do lastro de conhecimento sobre o passado.

Com pouco conhecimento histórico torna-se mais difícil debater com ideias diferenciadas, uma vez que não há no posicionamento político

${ }^{10}$ Bodo Von Borries é um dos pensadores alemães, da geração de Rüsen, que se dedicam a refletir dentro do campo da Didática da História. O texto de Saddi (2014) comenta sobre a construção desse campo na Alemanha.

${ }^{11}$ A expressão acontecimental está ligada ao conceito de História Tradicional, ligada a eventos. Utilizamos essa expressão pois se aproxima do conceito discutido por Braudel e Colin (événementielle) em seu trabalho sobre a estrutura de Longa Duração (Braudel, 1958). Usamos esse conceito aqui porque julgamos se aproximar do que Borries quis criticar em seu texto, uma vez que saber os fatos, o que estaria ligado à concepção de Histoire Événementielle, não é o suficiente para interpretá-los.

Araucaria. Revista Iberoamericana de Filosofia, Politica, Humanidades y Relaciones Internacionales, año $21, \mathrm{n}^{\circ} 41$. Primer semestre de 2019. Pp. 187-208. ISSN 1575-6823 e-ISSN 2340-2199 doi: 10.12795/araucaria.2019.i41.09 
referências contundentes aos saberes históricos afim de fornecer base para o desenvolvimento e articulação de ideias em ambientes e contextos de alteridade.

Todo esse processo acaba por desaguar na falta de legitimidade de ideias e defesa sobre algo. Com a falta de legitimidade e de conhecimento apela-se a lógica de negação do discurso do outro, para isso se utilizando de outras dimensões da Cultura Histórica. Essa dinâmica está inserida no senso comum quando pessoas proferem frases como: Você não pode me julgar, não me conhece!, ou Você não sabe pelo que passei!, ou ainda Você não sabe o que está falando, não estava lá!.

Dentro dessa lógica de negar o discurso do outro, por variados fatores, acaba por apontar para uma negação da própria história como ciência. Esse movimento fica evidente quando existem esforços, como o Brasil Paralelo, que se colocam na obrigação de contar a história até então escondida; ou discursos como o de que a pessoa que vivenciou o período tem mais legitimidade do que o historiador, como destacado por Cerri no vídeo do seu canal do YouTube ${ }^{12}$. Esses movimentos comprovam que ainda hoje é válido a formulação de Ferro (1989), a História é Vigiada.

Esses movimentos que tem encontrado espaço entre a juventude, como demonstram os dados, além de negar as narrativas produzidas pela metodologia histórica, também nega a própria ideia de Aprendizado Histórico. Isso porque, segundo Rüsen (2010b, p. 43), só existe Aprendizado Histórico quando o próprio sujeito insere sentido ao que está aprendendo, mas o que é possível perceber é que os sujeitos que, no caso, se colocam como intervencionistas não manifestam autonomia para tal, justamente por não apresentarem saberes básicos sobre o período dos generais.

\section{Consciência Utópica}

Os dados expostos no presente texto apontam que os jovens que se colocam como intervencionistas apresentaram o maior número de erros nas questões de conhecimento histórico postos no instrumento de pesquisa. Deste modo, fragiliza-se a legitimidade do discurso que eles assumem de que a quebra da democracia é o melhor para o Brasil.

Até aqui discutimos esses dados com o conceito de aprendizagem e Formação Histórica, dando foco a relação destes com o conhecimento histórico. Entretanto ainda há um conceito que pode servir para aprofundar a refelxão sobre os dados coletados e o que eles demonstram: Consciência Utópica. Para Rüsen (2010a, pp. 13-137) esse conceito está relacionado "à negação

12 “(HR16) Vovó sabe mais história que você (evidência anedótica)”. Disponível em: https://www. youtube.com/watch?v=yj75xrXmwwc. Acessado em: 01/11/2017. 
da realidade das circunstâncias dadas da vida", ou seja, Consciência Utópica "possui a função de orientar a existência humana por representações que vão, por princípio, além do que é, empiricamente, o caso" (RÜSEN, 2010a, p. 138).

Barom (2017, p. 99) explica que existe uma relação tensa e de limitação entre Consciência Utópica e Consciência Histórica, sendo a primeira negação da segunda, e é essa tensão que gera a orientação do cotidiano. Essa interpretação está de acordo com o que é apontado por Rüsen quando o pensador alemão afirma que a "função do Pensamento Histórico de orientar no tempo, decorre da divergência entre experiência e expectativa" (RÜSEN, 2010a, p. 145).

É ainda necessário destacar que Rüsen não enxerga de maneira negativa a Consciência Utópica, pelo contrário, a ver como necessária para a vida humana. Isto fica claro quando afirma que «utopias são, pois, os sonhos que os homens têm de sonhar com toda a força de seu espírito, para conviver consigo mesmos e com seu mundo, sob a condição de experiência radical da limitação da vida» (RÜSEN, 2010a, p. 138).

Uma díade muito semelhante a dinâmica proposta por Rüsen na relação entre Pensamento Histórico-Pensamento Utópico é a Espaço de Experiência-Horizonte de Expectativa proposta por Koselleck (2006b). Espaço de Experiência é "o passado atual, aquele no qual acontecimentos forma incorporados e podem ser lembrados" (KOSELLECK, 2006b, p. 309), já o Horizonte de Expectativa refere-se ao "futuro presente, voltado para o ainda-não, para o não experimentado, para o que apenas pode ser previsto" (KOSELLECK, 2006b, p. 310).

O Pensamento Utópico proposto por Rüsen está ligado ao futuro e, por não ser mediado pelas condições do presente, acabam por criticar o mesmo oferecendo uma possibilidade de futuro em que os desejos se realizem de forma perfeita, gerando esperanças que vão além do factível (RÜSEN, 2010a, pp. 137-138).

Esse modelo de pensamento acaba por participar do presente porque permite trazer, como expressa Koselleck (2006b, p. 310), o futuro para o agora e, sendo assim, esse porvir passa a atuar como motivação e orientação das ações do sujeito no seu cotidiano. Entretanto é preciso que esse futuro seja mediado pela experiência, do contrário "se perderia numa espécie de terra de ninguém para além das condições concretas do agir, ou seja, deixaria de poder funcionar como intenção do agir" (RÜSEN, 2010a, p. 139).

Outro autor que, de certa forma, chega a essa mesma conclusão refletindo sobre aspectos político-ideológicos práticos é Walter Benjamin. Dentro das críticas que esse marxista heterodoxo fez a socialdemocracia ele afirmou que "a classe operária desaprendeu nessa escola [socialdemocracia] tanto o ódio como o espírito de sacrifício. Porque um e outro se alimentam a imagem dos antepassados escravizados, e não dos descendentes liberados" (Benjamin, 
1987, p. 229). Ou seja, para Benjamin, a classe operária errou quando passou a olhar apenas para o futuro e seus sonhos, perdendo assim de vista tanto o presente quanto o passado de seus semelhantes. A consequência desse processo foi a perda da força para agir e lutar para chegar a esse objetivo almejado.

Destacamos aqui esses conceitos porque ao observar que os jovens que menos demonstraram saber, frente as questões postas pelo instrumento de pesquisa, são os que pedem a volta dos militares ao poder ou uma intervenção que se aproxime do modelo de governo empregado durante os anos de 1964 e 1985 é possível apontar o superávit de intenções, ou seja, uma ação do Pensamento Utópico.

Koselleck (2006b, p. 326) destaca que "quanto menor o conteúdo de experiência, tanto maior a expectativa que se extrai dele". É possível indicar através dos dados levantados de maneira empírica, e já apresentados aqui, que esse postulado reflete a realidade aprisionada pelo instrumento utilizado na pesquisa.

\section{Considerações Finais}

Esse processo do Pensamento Utópico que pode ser observado nos jovens que, mesmo sem, em sua maioria, terem demonstrado conhecimento de aspectos tidos como importantes do processo de início e de final do que foram os governos liderados pelos militares no Brasil pedem a volta do mesmo modelo, acaba por desaguar em uma geração de sentido $\mathrm{crítica}^{13}$ da modernidade.

Essa crítica se dá porque quando determinados jovens assumem um posicionamento intervencionista eles estão rompendo com características importantes da modernidade quanto à questão política. Fazemos esse apontamento levando em conta como traços modernos a mudança constante; por respeitar e mesmo valorizar as críticas às instituições, mantendo uma dinâmica dialética deste modo; a inovação na arte de governar frente aos problemas que se apresentam; a ideia de progresso e de avanço, dentro outros (HELLER e FEHÉR, 1994, p. 53,54,66,77).

Essa crítica ao modelo moderno tem relação com a falta de conhecimento histórico, para além das dificuldades com a Formação e aprendizagem histórica. Isso porque, uma vez que esses jovens encontrando dificuldades de apontar para saídas criativas com algum ineditismo resgatam modelos do passado esperando

\footnotetext{
${ }^{13}$ Geração de Sentido Crítica é uma das tipologias apresentadas por Rüsen para o produto da Consciência Histórica. Essa tipologia refere-se, em linhas gerais, quanto gera-se sentido negando os sentidos fundamentais estabelecidos em determinada sociedade. Aqui nos apropriamos, é importante destacar, desse conceito segundo a proposta que o autor fez na sua obra traduzida para o português sob o título História Viva: teoria da História: Formas e funções do conhecimento histórico. Referenciamos isso porque na obra publicada em 2015 pela editora da UFPR Rüsen (2015) não trabalha a Geração de Sentido Crítica como uma tipologia em si, mas como passagem para as demais.
} 
que eles sejam o suficiente para que solucionem os problemas da atualidade sem levar em conta as limitações desses mesmos modelos e as diferenças diacrônicas.

Também é possível levantar a possibilidade que esse futuro presente sem a tensão do passado presente reforça a cultura política autoritária brasileira. Esse reforço ocorre porque ao se chegar em momentos de crise ${ }^{14}$ e tendo apenas um superávit de esperança sem a carga de experiências suficiente para instrumentalizar a ação que permita alcançar essas esperanças acaba-se por terceirizar a responsabilidade para a resolução da crise. No caso particular do Brasil, costuma-se a optar por saídas autoritárias, revestidas de discursos com forte apelo a dimensão religiosa da Cultura Histórica e altamente centralizadas.

Há quem afirme que "é ingênuo supor que o conhecimento histórico seja bastante para nos livrar de recidivas autoritárias" (Motta, 2011, p. 109), mas ainda é necessário que alimentemos o que (...)

(...) na ideia da racionalidade humana, determinante da história como ciência e da Formação Histórica, encontra-se ainda [como] uma utopia: a representação de que a sociedade humana se efetiva mediante o reconhecimento mútuo e universal operado pela argumentação racional (RÜSEN, 2010a, p. 145).

Considerando a argumentação racional que Rüsen destaca como fruto da Formação e Aprendizado Histórico, essa utopia pode ser fortalecida pelos dados que demonstram que os que menos apresentaram conhecimento histórico são os que optaram por soluções autoritárias. Embora concordemos que não é apenas o conhecimento de fatos históricos que possibilitam uma mudança de posicionamento, mas que esta vem de acordo com o aprendizado e a Formação histórica, é possível apontar para a construção de saberes significativos para a construção de uma sociedade mais democrática, participativa e com cidadãos autônomos.

${ }^{14}$ Consideramos aqui o conceito de Crise utilizado por Rüsen (2015, p.56) que refere-se ao desafio dos processos de mudanças temporais, sendo a constituição história de sentido a superação da crise. 


\section{Bibliografia}

ARede, 2016. Cresce o número de escolas ocupadas em PG. [Online] Available at:

http://arede.info/ponta-grossa/115786/cresce-numero-de-escolasocupadas-em-pg?utm source=InstantArticleMW\&utm medium=referral?utm source=InstantArticleMW\&utm medium $=$ referral. [Acesso em 0406 2018].

Balestra, J. P. (jul./dez. de 2016). História e Ensino de História das Ditaduras no Brasil e na Argentina. Antiteses, 9(18), 249-274.

Barom, W. C. C. (2017). "Integração Latino-Americana e Consciência Histórica: A noção de pertencimento latino-americano de jovens brasileiros no ano de 2013". Tese (Doutoramento em Educação) - Universidade Estadual de Ponta Grossa. Orientador: Luis Fernando Cerri. (253 f.).

Benjamin, W. (1987). Sobre o Conceito da História. Em Benjamin, W., Magia e Técnica, Arte e Politica: Ensaios sobre a literatura e história da cultura ( $3^{\mathrm{a}}$ ed., pp. 222-232). São Paulo: Brasiliense.

Borries, B. V. (abr./jun. de 2016). Competência do pensamento histórico, domínio de um panorama histórico ou conhecimento do cânone histórico. Educar em Revista, 60, 171-196.

Bourdieu, P. (2013). Escritos de Educação (14a ed.). Petrópolis - RJ: Vozes.

Braudel, F. (Oct./Dec. de 1958). Histoire et Sciences Sociales : La longue durée. Annales. Économies, Sociétés, Civilisations, 13(4), 725-753.

Cardoso, O. (2008). Para uma definição de Didática da História. Revista Brasileira de História, 28(55), 153-170.

Cerri, L. F. (Inverno de 2001). Os Conceitos de Consciência Histórica e os Desafios da Didática da História. Revista de História Reginonal, 6(2), 93112.

Cerri, L. F. (2010). Didática da História: uma leitura teórica sobre a História na prática. Revista de História Regional, 15(2), 264-278.

Cerri, L. F. (2016). Un Bosque encima de la fossa común: dictaduras en la memoria de los jóvenes. Em L. Sánchez, M. C. Garcia, \& G. Grégoire (org.), La enseñanza de la Historia en debate: ¿enseñar desde el o presente o para el presente? ( $1^{\mathrm{a}}$ ed., pp. 81-98). Santa Rosa: Universidad Nacional de la Pampa.

Cerri, L., \& Duarte, G. R. (2012). Politização e consciência histórica em jovens brasileiros, argentinos e uruguaios. Diálogos (Maringá. Online), 16, 229256.

Ferro, M. (1989). A História Vigiada. (D. S. Pinheiro, Trad.) São Paulo: Martins Fontes. 
Freire, P. (1989). A Importância do Ato de Ler: em três artigos que se completam. São Paulo: Autores Associados : Cortez (Coleção Polêmicas do Nosso Tempo; 4).

Gramsci, A. (1991). Os Intelectuais e a Organização da Cultura (8 ${ }^{\mathrm{a}}$ ed.). Rio de Janeiro : Editora Civilização Brasileira.

Heller, A., \& Fehér, F. (1994 (editado em jun. de 1995)). O Pêndulo da Modernidade. Tempo Social, 6(1-2), 47-82.

Koselleck, R. (2006a). Historia Magistra Vitae. Em Koselleck, R., Futuro Passado: contribuição àsemântica dos tempos históricos (pp. 43-60). Rio de Janeiro: Contraponto,.

Koselleck, R. (2006b). Espaço de experiência e Horizonte de Expectativa: duas categorias históricas. Em Koselleck, R., Futuro Passado: Contribuição à Semântica dos Tempos Históricos (pp. 305-327). Rio de Janeiro: Contraponto : Ed. PUC-Rio.

Laville, C. (1999). A guerra das Narrativas: Debates e Ilusões em torno do Ensino de História. Revista Brasileira de História, 19(38), 125-138.

Motta, R. P. (2011). Pesquisar experiências autoritário-repressivas recentes: dilemas e riscos. Em F. NICOLAZZI, H. M. MOLLO, \& V. L. ARAÚJO, Aprender com a história? O passado e o futuro de uma questão (pp. 91114). Rio de Janeiro: FGV.

Neves, J. (2000/2001). Participação da Comunidade, Ensino de História e Cultura Histórica. Saeculum - Revista de História, 6/7, 35-47.

Notícias.cidades. (2016). PR: alunos protestam contra reforma. Acesso em 04 de 06 de 2018, disponível em http://noticias.band.uol.com. $\mathrm{br} / \mathrm{cidades} /$ noticia/ $100000827030 / \mathrm{pr}$-alunos-protestam-contraocupa $\% \mathrm{C} 3 \% \mathrm{~A} 7 \% \mathrm{C} 3 \% \mathrm{~A} 3 \mathrm{o}-\mathrm{de}-\mathrm{escolas} . \mathrm{html}$.

Penna, F. (jan./jun. de 2015). A total dúvida sobre o amanhã e o desafio de ensinar História: concepções de tempo na produção textual de alunos. História e Perspectivas, 53, 71-97.

Platanow, V. (2015). Jovem com cartaz pedindo intervenção militar é hostilizado no Rio. Acesso em 04 de 06 de 2018, disponível em http:// agenciabrasil.ebc.com.br/politica/noticia/2015-03/jovem-com-cartazpedindo-intervencao-militar-e-hostilizado-no-rio

Rüsen, J. (2001). Perda de Sentido e Construção de Sentido no Pensamento Histórico na Virada do Milênio. História: Debates e Tendências, 2(1), 9-22.

Rüsen, J. (2010b). Aprendizado Histórico. Em M. A. Schmidt, I. Barca, \& E. d. Martins (org.), Jörn Rüsen e o ensino de História (pp. 41-49). Curitiba: Editora UFPR.

Rüsen, J. (2015). Teoria da História: Uma teoria da história como ciência. (E. C. Martins, Trad.) Curitiba: Editora UFPR. 
Rüsen, J. (2010a). História Viva: teoria da História : Formas e funções do conhecimento histórico. (E. d. MARTINS, Trad.) Brasília: UnB.

Saddi, R. (2010). Didática da História como sub-disciplina da Ciência Histórica. História \& Ensino, 16(1), 61-80.

Saddi, R. (jul./dez. de 2014). Didática da história na Alemanha e no Brasil: considerações sobre o ambiente de surgimento da neu Geschichtsdidaktik na Alemanha e os desafios da nova didática da história no brasil. Opsis, 14(2), 133-147. 